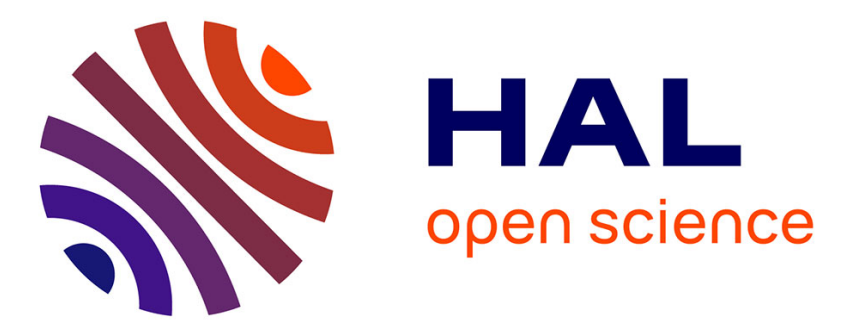

\title{
Imperfect automatic image classification successfully describes plankton distribution patterns
}

Robin Faillettaz, Marc Picheral, Jessica Y. Luo, Cédric Guigand, Robert K.

Cowen, Jean-Olivier Irisson

\section{- To cite this version:}

Robin Faillettaz, Marc Picheral, Jessica Y. Luo, Cédric Guigand, Robert K. Cowen, et al.. Imperfect automatic image classification successfully describes plankton distribution patterns. Methods in Oceanography, 2016, 10.1016/j.mio.2016.04.003 . hal-01324904

\section{HAL Id: hal-01324904 https: / hal.sorbonne-universite.fr/hal-01324904}

Submitted on 1 Jun 2016

HAL is a multi-disciplinary open access archive for the deposit and dissemination of scientific research documents, whether they are published or not. The documents may come from teaching and research institutions in France or abroad, or from public or private research centers.
L'archive ouverte pluridisciplinaire HAL, est destinée au dépôt et à la diffusion de documents scientifiques de niveau recherche, publiés ou non, émanant des établissements d'enseignement et de recherche français ou étrangers, des laboratoires publics ou privés. 


\section{IMPERFECT AUTOMATIC IMAGE CLASSIFICATION SUCCESSFULLY 2 DESCRIBES PLANKTON DISTRIBUTION PATTERNS}

4 Robin Faillettaz ${ }^{1}$; Marc Picheral ${ }^{1}$; Jessica Y. Luo ${ }^{2,3}$; Cédric Guigand ${ }^{2}$; Robert K. Cowen ${ }^{2,3}$; Jean5 Olivier Irisson ${ }^{1 *}$

$7 \quad{ }^{1}$ Sorbonne Universités, UPMC Univ Paris 06, CNRS, Laboratoire d'Océanographie de Villefranche,

8181 Chemin du Lazaret, 06230 Villefranche-sur-Mer, France

$9{ }^{2}$ Marine Biology and Fisheries, Rosenstiel School of Marine and Atmospheric Science (RSMAS),

10 University of Miami, Miami FL 33149, USA

$11{ }^{3}$ Oregon State University, Hatfield Marine Science Center, Newport OR 97365, USA

$13 *$ Corresponding author: irisson@normalesup.org 


\section{ABSTRACT}

16 Imaging systems were developed to explore the fine scale distributions of plankton $(<10 \mathrm{~m})$, but

17 they generate huge datasets that are still a challenge to handle rapidly and accurately. So far, 18 imaged organisms have been either classified manually or pre-classified by a computer program

19 and later verified by human operators. In this paper, we post-process a computer-generated 20 classification, obtained with the common ZooProcess and Planktonldentifier toolchain

21 developed for the ZooScan, and test whether the same ecological conclusions can be reached

22 with this fully automatic dataset and with a reference, manually sorted, dataset. The Random

23 Forest classifier outputs the probabilities that each object belongs in each class and we discard

24 the objects with uncertain predictions, i.e. under a probability threshold defined based on a $1 \%$

25 error rate in a self-prediction of the learning set. Keeping only well-predicted objects enabled 26 considerable improvements in average precision, $84 \%$ for biological groups, at the cost of 27 diminishing recall (by $39 \%$ on average). Overall, it increased accuracy by $16 \%$. For most groups, 28 the automatically-predicted distributions were comparable to the reference distributions and 29 resulted in the same size-spectra. Automatically-predicted distributions also resolved 30 ecologically-relevant patterns, such as differences in abundance across a mesoscale front or 31 fine-scale vertical shifts between day and night. This post-processing method is tested on the 32 classification of plankton images through Random Forest here, but is based on basic features 33 shared by all machine learning methods and could thus be used in a broad range of applications.

\section{KEYWORDS}

35 Imaging system; ISIIS; Automatic classification; Plankton distribution; Machine learning; Big 36 dataset 


\section{INTRODUCTION}

38 From the centimetre to kilometre-scales, hydrodynamics, predator-prey interactions and

39 behaviour strongly structure the patchy distributions of planktonic organisms in pelagic 40 environments (Davis et al., 1992; Pinel-Alloul, 1995; Lough and Broughton, 2007). At mesoscales

$41 \quad(10-100 \mathrm{~km})$ and submesoscales $(<10 \mathrm{~km})$, plankton distributions are primarily determined by

42 hydrological structures like fronts and eddies (Belkin, 2002; Belkin et al., 2009; Luo et al., 2014).

43 For example, convergent flows at frontal features can increase primary production (Grimes and

44 Finucane, 1991) and mechanically concentrate organisms (Bakun, 2006; Olson et al., 1994).

45 However, the influence of these structures may be counter-balanced by behaviour or other 46 biotic processes. Indeed, at fine scale $(<1 \mathrm{~km})$, diel vertical migrations can be a strong driver of 47 plankton distributions (Benoit-Bird and McManus, 2012; Neilson and Perry, 1990). At 48 microscales ( $<1 \mathrm{~m}$ to $10 \mathrm{~m}$ ), biotic interactions such as competition and predation are likely to 49 generate vertical gradients in the distribution of zooplankton. For example, in Monterey Bay, 50 predator avoidance is thought to vertically separate copepods, phytoplankton thin layers, and 51 gelatinous zooplankton predators (Greer et al., 2013). Off the coast of Massachusetts, 52 interactions between internal waves and foraging drives a temporary overlap between layers of 53 high copepod concentration and ichthyoplankton (Greer et al., 2014).

54 Historically, zooplankton and ichthyoplankton distributions have been sampled with pumps 55 (Herman et al., 1984) and regular or stratified plankton nets (e.g. regular: WP2, Bongo; e.g. 56 stratified: MOCNESS, BIONESS, MULTINET; Wiebe and Benfield, 2003). However, even depth57 stratified nets cannot typically resolve the fine and microscale processes at which biotic 58 interactions occur, because they usually sample (and integrate) over at least $10 \mathrm{~m}$ vertically and 59 much more horizontally. While pumps offer finer spatio-temporal resolution, they are often 60 limited to surface layers (<10 m depth -- Boucher, 1984; sometimes down to $100 \mathrm{~m}$ depth -61 Herman et al., 1984) and sample much smaller volumes (on average 50-60 $\mathrm{Lmin}^{-1}$ vs. $627,500 \mathrm{~L} \mathrm{~min}^{-1}$ for a small plankton net; Wiebe and Benfield, 2003).

63 In the last two decades, in situ imaging systems were developed with the aim of sampling 
64 microscale processes in the plankton and accelerating data processing using efficient automatic 65 classification techniques (MacLeod et al., 2010; Wiebe and Benfield, 2003). Several imaging 66 systems have emerged, tackling different ecological questions by targeting different size spectra 67 of organisms. The Video Plankton Recorder (VPR; Benfield et al., 1996) and the Underwater 68 Vision Profiler (UVP; Picheral et al., 2010) sample particles and zooplankton. The Shadow Image 69 Particle Profiling Evaluation Recorder (SIPPER; Samson et al., 2001), the ZOOplankton 70 VISualization imaging system (ZOOVIS; Bi et al., 2013) and the In Situ Ichthyoplankton Imaging 71 System, used for this study (ISIIS; Cowen and Guigand, 2008), target large zooplankton up to 72 several centimetres. ISIIS has been specifically designed to sample fish larvae that are patchy 73 and rare (Cowen et al., 2013). Therefore, it samples larger volumes of water compared to other 74 instruments (ISIIS: from 108 to $168 \mathrm{~L} \mathrm{~s}^{-1}$; UVP: typically $8 \mathrm{~L} \mathrm{~s}^{-1}$, up to $20.0 \mathrm{~L} \mathrm{~s}^{-1}$; SIPPER $9.2 \mathrm{~L} \mathrm{~s}^{-1}$; 75 ZOOVIS $3.6 \mathrm{~L} \mathrm{~s}^{-1}$; VPR: 10 to $17 \mathrm{~mL} \mathrm{~s}^{-1}$ ) and has proved to be particularly suited to describe the 76 fine-scale distribution of both ichthyoplankton (Cowen et al., 2013; Greer et al., 2014) and other 77 taxa, including gelatinous zooplankton (Luo et al., 2014; McClatchie et al., 2012). These imaging 78 systems generate large datasets of images. For example, in one hour, ISIIS records over 200 billion pixels (the equivalent of more than 200 GB of greyscale TIFF images), usually yielding

80 several hundred thousand objects of interest, that have to be identified. Manually processing 81 such big datasets has to be limited to few groups of interest (e.g. Greer et al., 2015, 2014; Luo et 82 al., 2014; McClatchie et al., 2012) but remains time prohibitive. Developing accurate automatic 83 identification processes for such datasets is still a challenge (Benfield et al., 2007; Cowen et al., 84 2013; Culverhouse et al., 2006) that needs to be solved in order to fully resolve microscale 85 processes.

86 Imaging data are typically handled in a three-step process: first, detecting and segmenting 87 relevant objects (or regions of interest) from raw images; then measuring features of each 88 object (such as size, aspect ratio, etc.); and finally using these features to classify the objects 89 into biologically/ecologically relevant groups through machine learning algorithms. Several 90 automatic identification procedures have already been tested on plankton datasets of a few 91 thousand images using various classifiers: Random Forest (e.g. Bell and Hopcroft, 2008), Support 92 Vector Machines (e.g. Hu and Davis, 2005), Bayesian models (Ye et al., 2011) or neural networks 
93 (e.g. Davis et al., 2004). Some also combined several classifiers to improve prediction accuracy 94 (Hu and Davis, 2005; Li et al., 2014; Zhao et al., 2010). While the algorithms differ, all of these 95 classifiers have in common the fact that they result in a final score (often a probability) for an 96 object to be in each class and attribute the object to the class with the highest score. This 97 predicted class is often the only information that is retained from the classifier. So, while 98 classification is typically viewed as a yes-or-no problem, the real outputs from the classifiers are 99 actually continuous.

100 In this study, we take the example of the commonly-used image processing and identification 101 toolchain ZooProcess and Plankton Identifier (PkID) (Gorsky et al., 2010). The software was first 102 developed for the ZooScan (laboratory plankton scanner) and then extended to the UVP 103 (Picheral et al., 2010) and other imaging systems. ZooProcess segments objects from the full 104 image and computes a set of descriptive features (grey levels, length, width, area, shape, etc.) 105 that are then used by PkID through various classification algorithms (Support Vector Machine, 106 Neural network, Random Forest, etc.), although Random Forest (Breiman, 2001) has proven to 107 be the most accurate and is now used routinely (Gorsky et al., 2010). This software suite is free, 108 open-source, easy to install, and well supported. Therefore, it is widely distributed worldwide 109 and used by 60 research teams from the tropics to the poles (e.g. France (Vandromme et al., 110 2011); New-Caledonia (Smeti et al., 2015); Antarctica (Espinasse et al., 2012)). It is most 111 commonly used as a computer-assisted identification system, whereby the classifier proposes 112 identifications that are then validated by human operators for all objects.

113 ZooProcess and PkID offer appropriate tools to handle ISIIS data but the amount of data 114 generated by ISIIS makes human validation impractical. For example, validating the 115 identifications of the 1.5 million objects used as a reference in this study took seven full-time 116 months; a few days of ISIIS deployments typically yield from ten to a hundred million objects. 117 However, given the size and spatial resolution of the dataset, even a subset of it is likely to 118 contain relevant ecological information, at least at the meter to $10 \mathrm{~m}$ scale. Here, we propose to 119 discard objects with a low classification score (i.e. the least likely to be correctly identified) and 120 assume that all remaining objects are correctly classified, hence bypassing the validation step. 
121 Most other studies compare automatic classification methods using only classification metrics

122 (e.g. precision, recall). We suggest that a more biologically relevant approach is to examine

123 whether the same ecological patterns can be detected in datasets generated by various

124 methods. Here we compare the same data either manually identified (hereafter the reference

125 dataset) or automatically classified and further filtered based on classification score (hereafter

126 the predicted dataset). We specifically explore the fine-scale spatial distribution of zooplankton

127 across a frontal structure, its relationship with the environment, the size distribution of

128 planktonic groups as well as their diel vertical migration patterns.

\section{MATERIALS AND METHODS}

\section{Description of ISIIS}

131 The In Situ Ichthyoplankton Imaging System (ISIIS) is a towed underwater imaging system

132 (Cowen and Guigand, 2008). It uses backlight shadowgraph imaging, which makes it ideally 133 suited for small and often transparent planktonic organisms in a consistent manner. The version

134 of ISIIS used here was slightly modified from that of Cowen and Guigand (2008). The line-scan

135 camera imaged a $10.5 \mathrm{~cm}$-tall field of view with a $50 \mathrm{~cm}$ depth of field. With a line-scan camera,

136 the image is created by the movement of the instrument and scanning at $28 \mathrm{kHz}$ produced a 137 continuous image when towed at $2 \mathrm{~m} \mathrm{~s}^{-1}$ (4 knots). These settings resulted in a sampling rate of $138108 \mathrm{~L} \mathrm{~s}^{-1}$. Additionally, ISIIS is equipped with environmental sensors recording temperature, 139 conductivity (hence salinity and density), oxygen, chlorophyll a fluorescence and 140 photosynthetically active radiation (PAR) at a rate of $2 \mathrm{~Hz}$.

141 Test data

142 ISIIS was deployed for two transects across the Ligurian current, a coastal jet that creates a 143 permanent, mesoscale front. The current delineates a coastal, a frontal and an offshore zone, 144 with characteristic hydrological properties (Sammari et al., 1995) and biological communities 145 (Boucher et al., 1987). One transect was conducted at night, the other during the following day, 
146 in July 2013. Both transects were conducted on the same line, though the night transect 147 sampled from onshore to offshore, and the day transect sampled from offshore to onshore.

148 Thanks to moveable fins, ISIIS sampled the water column in a tow-yo fashion, between the 149 surface and $100 \mathrm{~m}$ depth, with a vertical speed of $0.2 \mathrm{~m} \mathrm{~s}^{-1}$. The images in this study come from

15013 down-casts of the night transect and 7 down-casts of the day transect, which were the only 151 ones fully processed of the $\sim 26$ total up- and down- casts of each transect.

\section{Image pre-processing}

153 ISIIS collected a continuous stream of pixels, 2048 pixels in height. The stream was cut into 154 square $2048 \times 2048$ frames by the acquisition software (example in Figure 1). Because the 155 camera was continuously scanning the same line, a single speckle or scratch along the optical 156 path would create a continuous streak in the resulting 2D image. These streaks were removed 157 by dividing each frame by the average of the previous 50 consecutive frames and normalising 158 the result to $[0,255]$ in grey intensity, a process known as flat-fielding.

\section{Segmentation}

160 The shadows of planktonic organisms or particles imaged by ISIIS appeared dark on a light 161 background. All images were thresholded at the 195 grey level; i.e. adjacent pixels darker than 162195 (255=white, $0=$ =black) were considered as objects of interest. The flat-fielding procedure 163 resulted in an almost white background and well contrasted objects (Figure 1). Therefore, the 164 detection of objects was not very sensitive to the threshold value and 195 was chosen after a 165 few tests.

166 Small objects were difficult to identify reliably, even for human operators. Only objects larger 167 than $250 \mathrm{px}$ in area (equivalent to $18 \mathrm{px}$ in diameter for a spherical object) were considered in 168 this study. With a pixel resolution of $51 \mu \mathrm{m}$, this converts to an area of $0.6 \mathrm{~mm}^{2}$ and an 169 equivalent diameter of $920 \mu \mathrm{m}$.

170 All objects with sufficient size and darkness were segmented out of the frames (Figure 1 171 exemplifies which objects were considered and which were not) and the region outside of the 
172 object itself was made pure white. A total of 1.5 million objects were detected.

173 Feature extraction

174 The purpose of this study is to optimise an existing classification procedure a posteriori.

175 Therefore, the feature extraction was based on the standard configuration in ZooProcess/PkID

176 and is not described in detail here (please refer to Gasparini and Antajan, 2013; Gorsky et al.,

177 2010). Briefly, 37 features were measured by ZooProcess, and 9 additional variables were

178 derived by PkID from the original 37 features. These features characterised each object's size

179 and shape (length of the minor and major axes of the best fitting ellipse, Feret diameter,

180 circularity, symmetry, aspect ratio), transparency (five measures of grey levels: mean, mode,

181 standard deviation, minimum, maximum), and aspect (grey level histogram descriptors such as

182 skewness, cumulative histograms, etc.). When combined, those features can characterise object

183 classes; for example, small, dark, ovoid objects with a large Feret diameter compared to their

184 overall size are probably copepods with their antennae extended. Therefore, they serve as the 185 basis for automatic classification. 


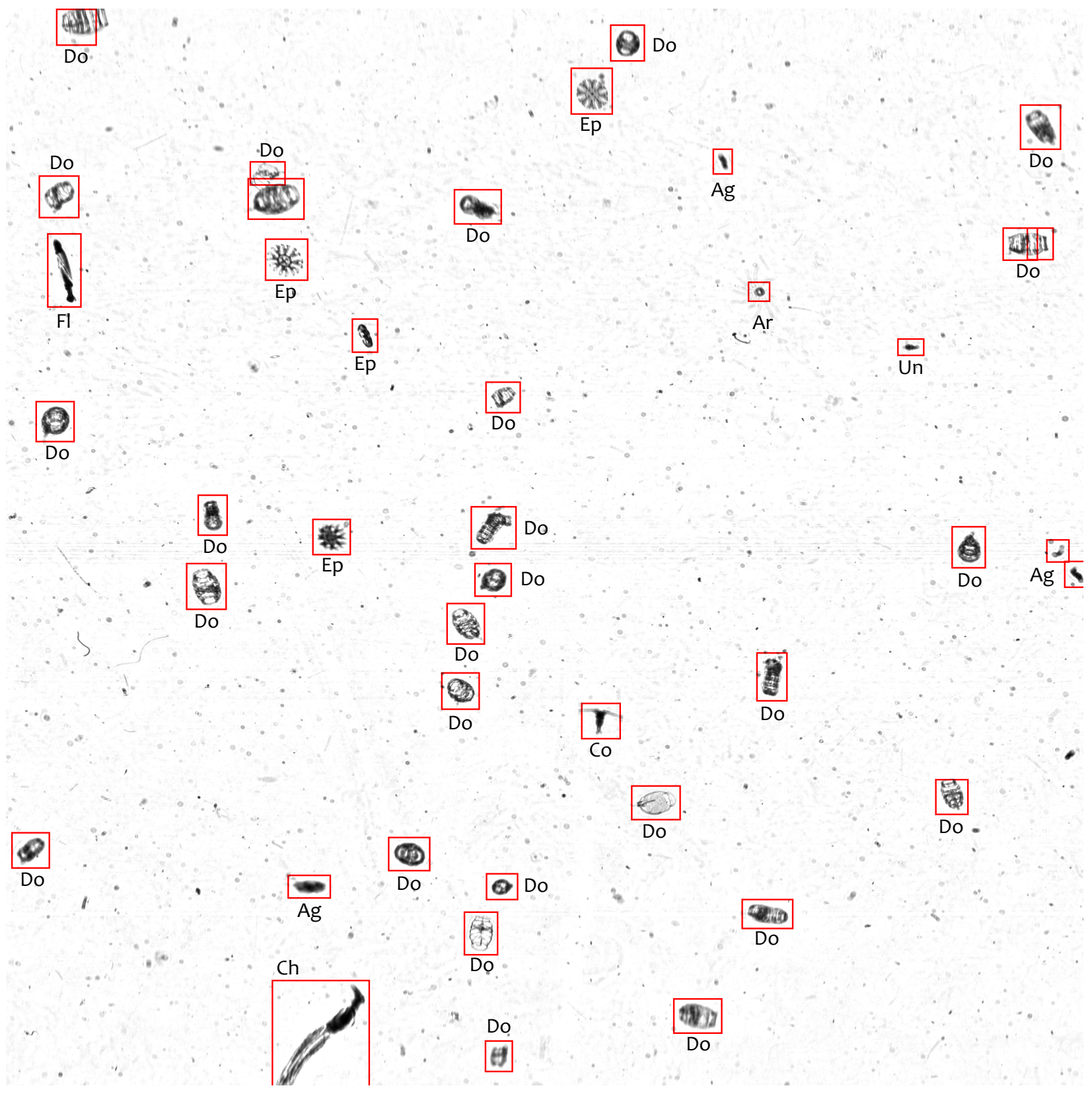

Figure 1. Example of a flat-fielded 2048 x 2048 pixels frame collected by ISIIS. The bounding box of objects extracted and measured is drawn in red. Those objects are labelled (Ag:

189 aggregates; Ar: Trachymedusae Arctapodema spp; Ch: chaetognath; Co: calanoid copepod; Do:

190 doliolid; Ep: Pelagia noctiluca ephyrae; Fl: fish larva; Un: unidentified). Note that, on rare 191 occasions, some small-bodied and transparent organisms, such as doliolids, were either 192 truncated or split into several objects and then became hardly identifiable. 
194 Supervised classification techniques require a set of identified and measured objects to learn 195 the differences between classes based on their features. Our learning set comprised 14 biotic 196 and abiotic classes with a target size of 200 objects per class (see Table 1), a number which 197 proved to be appropriate for previous ZooProcess/PkID projects (Gorsky et al., 2010). The most 198 numerous classes in the data (noise in particular) were also inflated in the learning set, to get a 199 total of 5979 objects. Objects in the learning set were chosen to be representative of the 200 diversity of each class.

201 All 1.5 million segmented objects were classified into these 14 classes by a Random Forest 202 classifier using the 46 measured features (Gorsky et al., 2010). The parameters of the classifier 203 were left at the appropriate defaults in PkID: 100 trees, bagging of 1, 6 features randomly 204 selected per tree, leaf size of 2 objects.

205 Finally, three trained operators validated the classification of each object, yielding a completely 206 manually-identified dataset of 1.5 million objects, hereafter referred to as the reference dataset.

207 Table 1. Name, number of objects in the learning set (n) and description of classes. First non208 living objects or artefacts, then biological organisms.

\begin{tabular}{lll}
\hline Class & $\mathrm{n}$ & Description, taxonomical identification \\
\hline \hline Dark aggregates & 314 & Solid, opaque marine snow \\
Light aggregates & 489 & Marine snow (larvacean houses, mucus, etc.) \\
Fibers & 433 & Thin fibers and fecal pellets \\
Noise & 2296 & Noise generated by water density changes \\
Tentacles & 224 & Pelagia noctiluca tentacles \\
\hline Copepods & 349 & Mainly calanoid copepods \\
Doliolids & 209 & Thaliacean, Family Doliolidae \\
Fish larvae & 289 & Fish larvae \\
Trachymedusae & 200 & Trachymedusae (e.g. Arctapodema spp) \\
Diatom chains & 342 & Phytoplankton, diatoms chains
\end{tabular}


Acantharia radiolarians

Radiolarian colonies

Solitary radiolarians

Shrimps
213 Radiolaria, Order Acantharia

255 Radiolaria, Order Colodaria, in colonies

267 Radiolaria, Order Colodaria, solitary

99 Shrimp-like organisms (e.g. Mysidacae or Euphausiacae)

\section{Data filtering and optimisation of the classifier precision}

To detect meaningful ecological patterns in the distribution of a computer-predicted class, there needs to be sufficiently high confidence that objects in that class belong to the same taxonomic group. In terms of classifier performance, this requires high precision (precision = proportion of correctly classified objects in a predicted class). With low precision, a predicted class would be a heterogeneous mixture of various taxonomic groups, the distribution of which cannot be interpreted ecologically. Conversely, for high frequency imaging datasets, the data are often in sufficient quantity that a subsample of the whole dataset would be enough for detecting ecological patterns. In terms of classification metrics, a low recall may be acceptable (recall = proportion of the total number of objects of a class that are predicted in that class). Therefore, we suggest that, to detect ecological patterns in a high frequency dataset, particularly for common taxa, precision is more important than recall. To test this hypothesis, we filtered out the most likely mistakes in the computer-predicted dataset (to increase precision), at the cost of discarding some correctly identified objects (hence decreasing recall), and then compared the resulting dataset against the reference set.

The probabilities for each object to be in each class (i.e. the final output of the classifier) were used as the filtering criterion. All objects assigned to a given class were ranked in increasing order of probability. All objects with probability above a threshold were kept and assumed to be correctly identified; other objects, with probability equal to or lower than the threshold, were considered to be potentially wrong and were discarded. Since precision needs to be controlled, the threshold should be set to result in a given precision. For example, picking the probability of the first wrongly identified object as the threshold would yield $100 \%$ precision (all objects ranked above the first false positive are correctly classified). Here, a $1 \%$ error rate (99\% precision) was deemed acceptable. Error rates lower than $1 \%$ resulted in discarding $3 \%$ more 
233 objects while improving precision by only 0.2. Higher error thresholds resulted in low precision 234 when applied to the whole dataset (average precision with threshold at $10 \%=54$, at $5 \%=60.1$, at $2351 \%=76.9)$. A $1 \%$ error threshold allowed us to increase precision significantly and still keep a 236 representative percentage of objects.

237 The computation of thresholds was done with the learning set only, because in operational 238 conditions, only the identifications of the objects in the learning set are known. The class 239 probability of each object in the learning set was predicted using 2-fold cross-validation 240 repeated 50 times, using the Random Forest classifier in PkID. The probabilities were averaged 241 over the 50 repetitions, objects were assigned to the class of highest probability, and probability

242 thresholds at $1 \%$ error were computed in each class. Those thresholds, computed on the 243 learning set, were then applied to the predictions of the 1.5 million objects and the subset of 244 objects that was kept constituted the predicted dataset. Thus, once the objects in the learning 245 set are identified manually (which is required for prediction anyway), this precision optimisation 246 method requires only computation, no further human validation effort.

\section{Consequence of data filtering on classification metrics}

248 By construction, the chosen thresholds resulted in exactly $99 \%$ precision on the learning set.

249 Because all 1.5 million objects in the reference set were actually identified in this exercise, the 250 precision, recall and F1 score $(2 \times$ precision $\times$ recall $/($ precision + recall $))$ could be computed for 251 each class over the whole dataset, before and after the filtering process. This allowed us to 252 check whether the precision after filtering approached 99\% on the whole dataset as well and 253 how much this improvement in precision cost in terms of decrease in recall.

\section{Comparison of size spectra}

255 The size structure of planktonic communities is often considered as a proxy to study the transfer 256 of energy through the food web and the export and sequestration of carbon (Legendre and Le 257 Fèvre, 1991). It could be expected that smaller objects would be less defined, would therefore 258 be predicted with lower confidence (i.e., lower probabilities) and may be preferentially filtered 259 out by our method. To assess this, size spectra (i.e., probability density distributions of sizes) 
260 were estimated with a kernel method (Gaussian kernel with a $0.25 \mathrm{~mm}$ standard deviation) and 261 compared in the reference and predicted dataset.

\section{Statistical comparisons of spatial distributions}

263 Individual objects were counted over $1 \mathrm{~m}$ depth bins along the undulating trajectory of ISIIS and

264 counts were transformed into concentrations by dividing by the volume sampled in each bin.

265 This resulted in maps of the concentration of each class of organism across depth (0-100 m) and

266 distance from the coast $(0-60 \mathrm{~km})$ for each transect (for examples see Figures 3 and 4).

267 The similarity between the maps for the reference and predicted datasets was assessed using 268 the $t$-test modified by Dutilleul (Dutilleul et al., 1993; H0: no correlation between the maps, H1: 269 significant correlation between the maps), as well as the Pearson and Spearman correlation 270 coefficients. On a map, observations close to each other are usually similar; this spatial 271 autocorrelation means that observations close to each other are not independent and that the 272 number of actual degrees of freedom is lower than the apparent sample size. The Dutilleul $t$-test 273 corrects the number of degrees of freedom based on the spatial autocorrelation of the data 274 (computed as Moran's $I$ ) and is therefore appropriate to avoid over-estimating the similarity of 275 spatial patterns.

276 Because diel-vertical migration is such a widespread behaviour in marine ecosystems (Hays, 277 2003) and strongly influences survival through predator-avoidance and foraging in many taxa 278 (Neilson and Perry, 1990), data were specifically inspected in the vertical dimension. Average 279 vertical distributions were computed for each group and each transect (hence separating day 280 and night). Reference and predicted vertical distributions were compared with the version of 281 Kolmogorov-Smirnoff test modified by Solow et al. (2000), which specifically takes into account 282 autocorrelation along depth caused by the patchiness of plankton.

283 By construction, concentrations were lower in the predicted dataset than in the reference 284 dataset, because the former is a subset of the latter. Before the comparisons described above, 285 concentrations were normalised to a maximum value of 1 for each class in each transect, by 286 dividing by the maximum concentration recorded. This put the focus on distribution patterns, 
287 rather than actual concentration values, which were poorly estimated when recall was low 288 anyway.

289 Finally, the predicted and reference datasets are not independent (one is a subset of the other) 290 and the absolute values of the test statistics and $p$-values are therefore biased. The relative 291 values, among classes, are informative however.

\section{Comparison of ecological patterns}

293 The frontal structure across which the transects were sampled is characterised by an inshore294 offshore gradient of increasing salinity, with a front that can be delineated by the 38.2 and 38.3 295 isohalines (Sammari et al., 1995) and is expected to strongly structure zooplankton communities 296 (e.g. Boucher, 1984; Pedrotti and Fenaux, 1992). Beyond comparing the distribution maps for 297 the reference and predicted datasets statistically, the results were interpreted with respect to 298 the frontal structure to check whether the ecological patterns were the same. In addition, the 299 relationships between planktonic abundances and environmental variables were inspected in 300 the reference and predicted datasets. The variables inspected were: salinity, which best marks 301 the front, temperature, which is strongly stratified vertically, chlorophyll $a$ fluorescence, which

302 marks a clear Deep Chlorophyll Maximum (DCM), and oxygen concentration, which depends 303 both on the frontal structure and on the DCM. When the relationships could be considered 304 linear, the slopes were estimated through Generalised Linear Models (GLM) with Poisson errors 305 and statistically compared between the two datasets using ANOVA.

306 Similarly, beyond comparing vertical distributions statistically, we assessed whether the range 307 and strength of diel vertical migrations could be as readily detected in the predicted dataset 308 than in the reference dataset. Within each class, day and night distributions were compared 309 with the Solow-Kolmogorov-Smirnov test and the value of its statistic was compared between 310 reference and predicted data. The day-night shift in the depth centre of mass of the 311 distributions (mean of depth weighted by abundance at that depth, $Z_{c m}$; Irisson et al., 2010) was 312 computed and compared between the reference and predicted datasets. 
314 Abrupt changes in water temperature around the thermocline generated large density

315 differences, which are unfortunately well captured on shadowgraphs. These numerous objects

$316(n=1,287,302)$ were classified as "Noise". Another abundant class of objects were tentacles of 317 the medusa Pelagia noctiluca $(n=8,106)$, which occasionally got stuck on ISIIS and were imaged

318 constantly. These two classes of objects are not biologically relevant in the present study, but 319 were abundant and predicted with high precision (>95\%), and were thus both omitted from the 320 subsequent analyses.

\section{RESULTS}

\section{Consequences of data filtering on classification metrics}

323 Discarding low probability images considerably increased precision, by $37 \%$ on average (Table

324 2). While probability thresholds were set to yield $99 \%$ precision on the cross-validated learning 325 set, precision was lower when the thresholds were applied to the whole dataset. This was 326 expected, because the $\sim 6000$ images in the learning set cannot fully represent the variability in 327 the whole dataset (1.5 million images). The average precision of the biological categories after 328 filtering was $84 \%$. The trachymedusae and Acantharia radiolarians displayed the lowest 329 precision (61.9\% and $65.4 \%$ respectively) but this already was an improvement of more than $33050 \%$ compared to the situation before filtering.

331 To reach these precision levels, a large amount of images had to be discarded, leaving only $33228.1 \%$ of the objects from the original dataset ( $n=39,758$, excluding "noise" images). The 333 percentage of objects retained ranged from $8.5 \%$ for fibres $(n=557)$ to a maximum of $63.7 \%$ for 334 solitary radiolarians $(n=8,569)$. As a consequence, on average, filtering decreased recall by $39 \%$ 335 and F1 score by $7.8 \%$. However, the improvement in precision dominated the effect of the 336 decrease in recall, because classification accuracy of the whole dataset improved from $40.2 \%$ to $33756.3 \%$ after filtering. 
338 Table 2. Classification metrics before and after filtering out objects with low prediction

339 confidence: number of particles before filtering (n); percentage of data kept after filtering;

340 precision, recall, and F1 score before and after filtering, and difference (after - before).

341 Improvements (positive differences) are bolded. Non-living groups are presented first, groups of

342 biological interest second.

\begin{tabular}{lllllllllllll}
\hline & & \multicolumn{4}{c}{ Precision } & \multicolumn{3}{c}{ Recall } & \multicolumn{5}{c}{ F1 } \\
Class & $\mathrm{n}$ & \%kept & before & after & diff & before & after & diff & before & after & diff \\
\hline \hline Dark aggregates & 60164 & 6.5 & 77 & 95 & $\mathbf{1 9}$ & 50 & 7 & -43 & 60 & 7 & -54 \\
Light aggregates & 4209 & 4.2 & 8 & 17 & $\mathbf{9}$ & 53 & 4 & -49 & 14 & 4 & -10 \\
Fibers & 8055 & 6.9 & 46 & 85 & $\mathbf{3 8}$ & 56 & 7 & -49 & 51 & 7 & -44 \\
\hline Copepods & 17459 & 22.4 & 54 & 88 & $\mathbf{3 4}$ & 72 & 22 & -49 & 62 & 22 & -39 \\
Doliolids & 30478 & 40.2 & 80 & 95 & $\mathbf{1 6}$ & 64 & 40 & -24 & 71 & 40 & -31 \\
Fish larvae & 802 & 23.2 & 12 & 80 & $\mathbf{6 7}$ & 62 & 23 & -39 & 21 & 23 & $\mathbf{3}$ \\
Trachymedusae & 524 & 50.6 & 9 & 62 & $\mathbf{5 3}$ & 79 & 51 & -29 & 16 & 51 & $\mathbf{3 5}$ \\
Diatom chains & 11015 & 28.6 & 75 & 97 & $\mathbf{2 2}$ & 72 & 29 & -43 & 73 & 29 & -45 \\
Acantharia radiolarians & 1021 & 18.9 & 7 & 65 & $\mathbf{5 8}$ & 74 & 19 & -55 & 14 & 19 & $\mathbf{5}$ \\
Radiolarian colonies & 4367 & 16.7 & 24 & 94 & $\mathbf{7 0}$ & 62 & 17 & -45 & 35 & 17 & -18 \\
Solitary radiolarians & 13049 & 65.7 & 68 & 88 & $\mathbf{1 9}$ & 89 & 66 & -23 & 77 & 66 & -12 \\
Shrimps & 213 & 52.6 & 51 & 89 & $\mathbf{3 8}$ & $\mathbf{7 4}$ & 53 & -21 & 60 & 53 & -7 \\
\hline
\end{tabular}

343 Comparison of size spectra in the reference and predicted datasets

344 In most classes, the size distribution of objects in the automatically predicted dataset and in the

345 reference dataset were closely related (Figure 2). However, in three groups (fish larvae,

346 radiolarian colonies, and shrimps), the shape of the spectrum was conserved but the occurrence

347 of small objects was under-estimated. In particular, the mode of the spectrum (i.e. the most

348 frequent size class) was larger by $1.3 \mathrm{~mm}$ for fish larvae in the predicted dataset compared to

349 the reference dataset, by $6 \mathrm{~mm}$ for radiolarian colonies and by $2.8 \mathrm{~mm}$ for shrimps (Figure 2). 

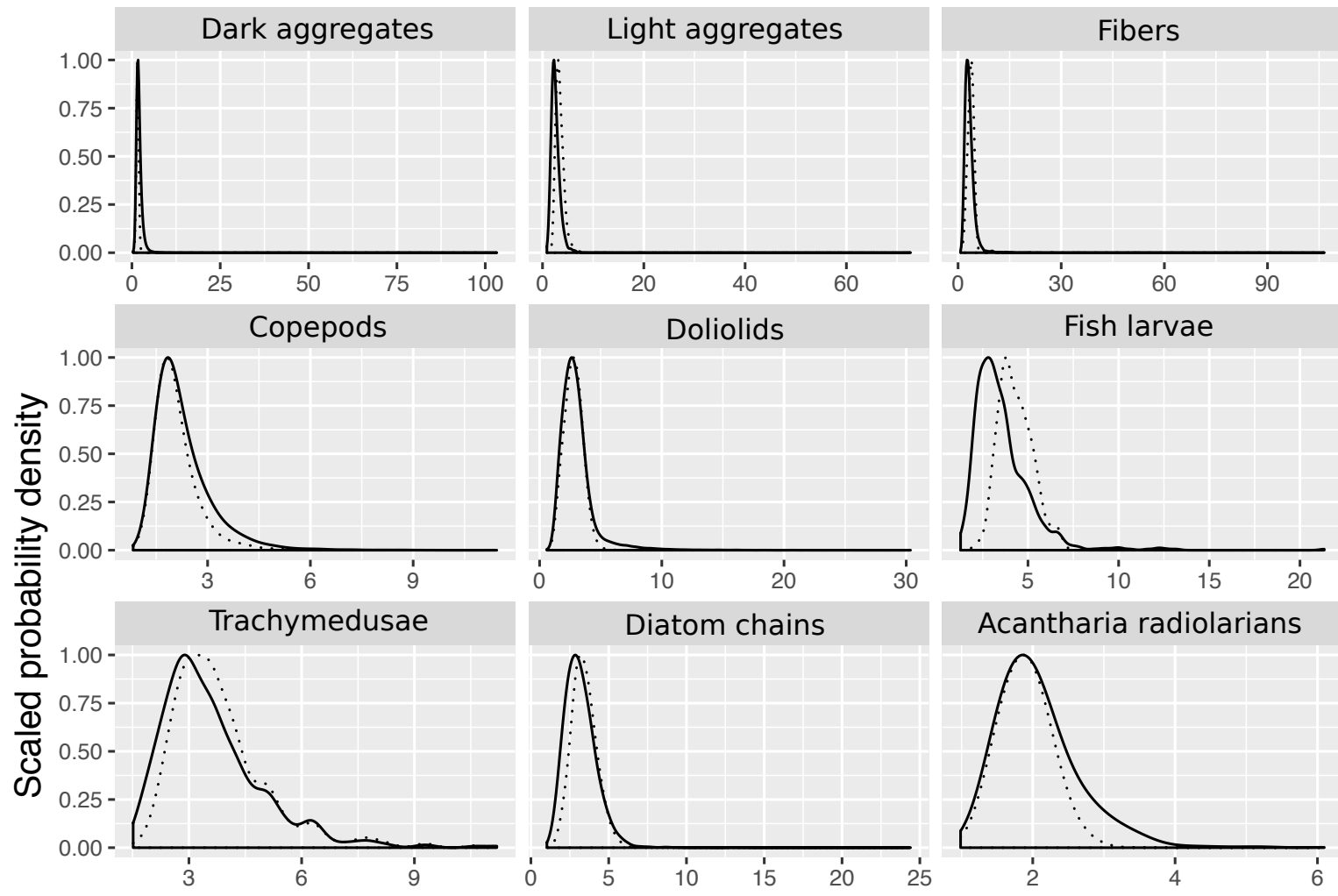

Fish larvae
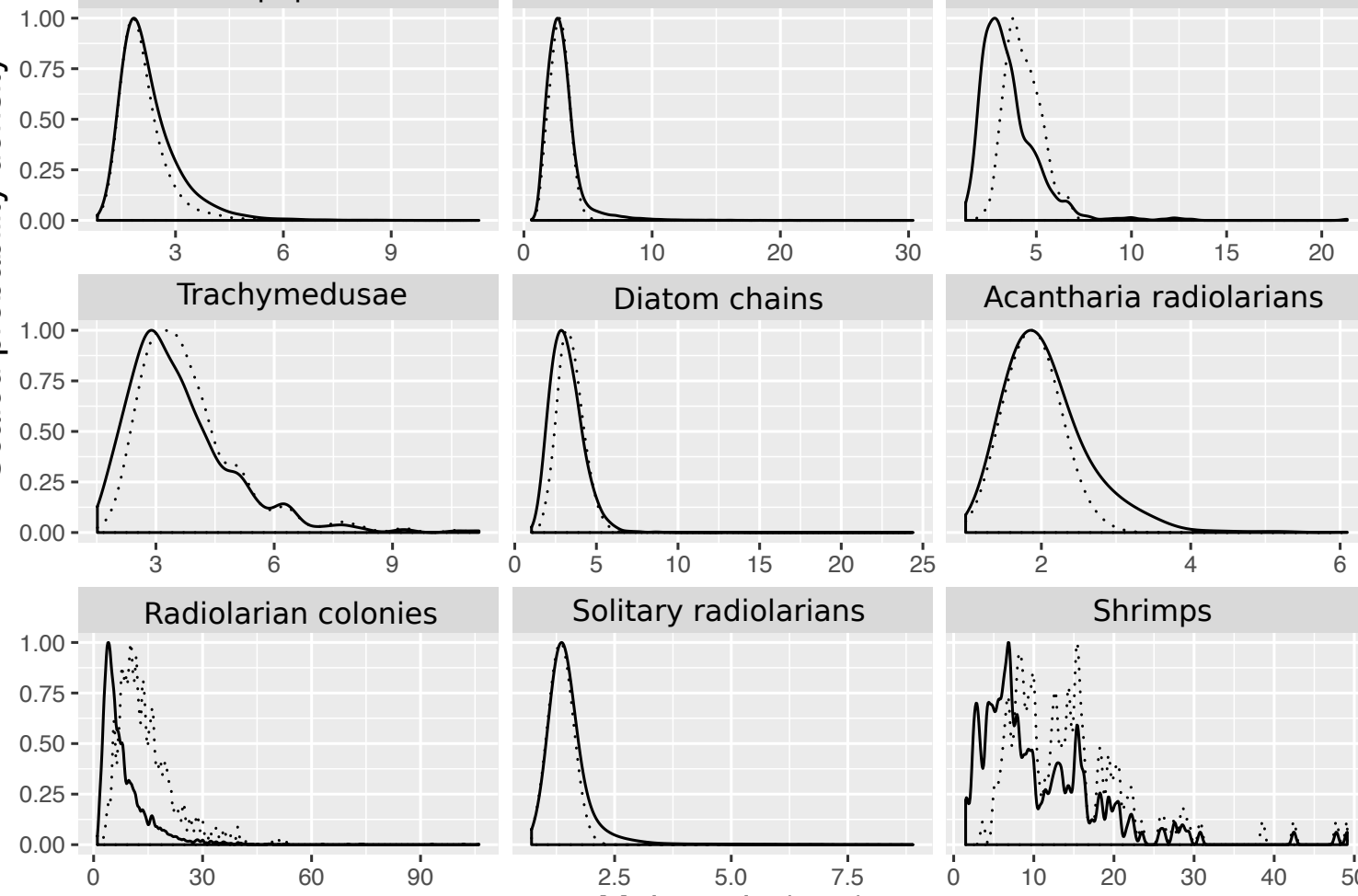

$$
\text { Solitary radiolarians }
$$
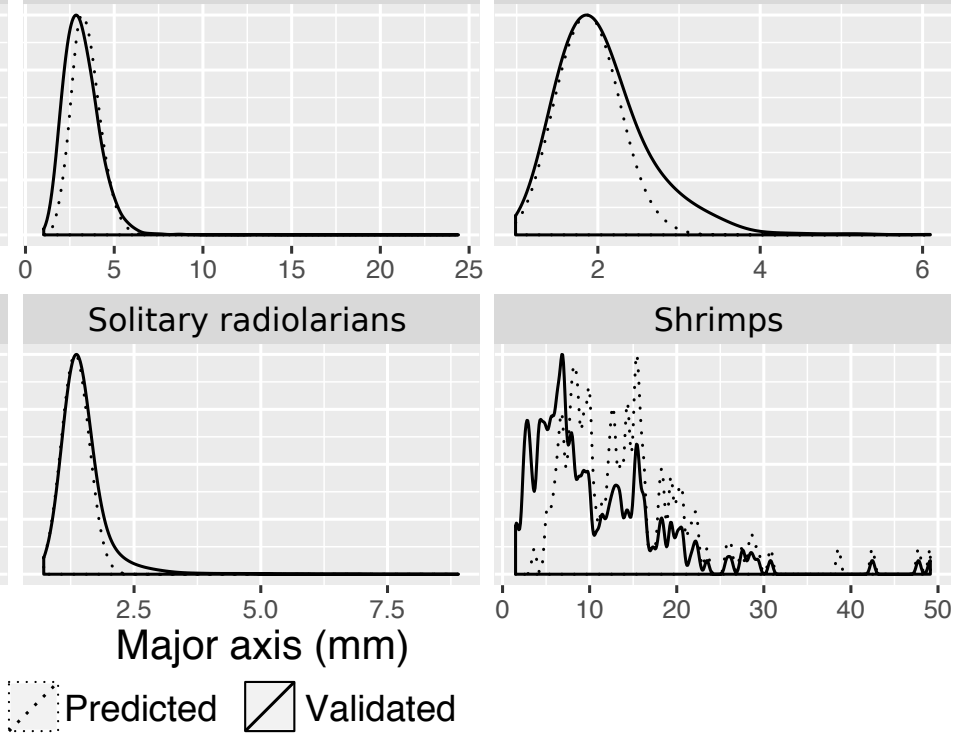

351 Figure 2. Per-class size spectra in the reference (solid lines) and automatically predicted and

352 filtered (dotted lines) datasets. Probability density distributions of sizes were scaled between 0

353 and 1 to focus attention on the shapes of the distribution rather than the differences in the

354 number of objects between the two datasets. The minimum size of objects considered was 250

355 pixels in area, resulting in $\geq 920 \mu \mathrm{m}$ in major axis.

356 Distribution of plankton with respect to the front

357 The automatically predicted and filtered spatial distributions of most taxa and particles were

358 significantly correlated with the reference distributions in 20 of the 22 groups at the $p<0.001$ 
359 level (Table 3; Figure 3). Correlation coefficients were also very high (seven classes with $r>0.7$, 360 and eight additional classes with $r>0.5$ ). The only two exceptions are fish larvae and shrimps in 361 the day transect, both of which were very rare.

362 At the chosen 99\%-precision filtering level, so many images of fish larvae and fibres were 363 discarded that the resulting spatial distributions were very sparse $(14.9 \%$ and $8.5 \%$ of images 364 left, respectively; Figure 4). Such sparse distributions would clearly not be interpreted 365 ecologically, given how little data are left and how much is discarded. So, information is lost but 366 at least no wrong conclusions would be drawn. In addition, even in those cases, the locations of

367 the maximum concentration zones were properly captured in the predicted dataset; there were 368 just too few objects to represent the finer patterns (Figure 4).

369 Table 3. Statistical comparisons of spatial distributions between the reference and predicted 370 datasets with three statistics: Dutilleul modified $t$-test (statistic, recomputed degrees of

371 freedom and $p$-value), Pearson's correlation coefficient and Spearman's rank correlation 372 coefficient. NB: no light aggregates were observed at night.

\begin{tabular}{|c|c|c|c|c|c|c|}
\hline \multirow[b]{2}{*}{ Class } & \multirow[b]{2}{*}{ Transect } & \multicolumn{3}{|c|}{ Dutilleul $t$-test } & \multirow[b]{2}{*}{ Pearson's $r$} & \multirow[b]{2}{*}{ Spearman's rho } \\
\hline & & F-stat & DoF & $p$-value & & \\
\hline \multirow[t]{2}{*}{ Dark aggregates } & Night & 29.99 & 35 & $p<0.001$ & 0.66 & 0.68 \\
\hline & Day & 24.11 & 20 & $p<0.001$ & 0.68 & 0.74 \\
\hline Light aggregates & Day & 10.05 & 76 & $p<0.01$ & 0.11 & 0.34 \\
\hline \multirow[t]{2}{*}{ Fibers } & Night & 103.22 & 155 & $p<0.001$ & 0.38 & 0.62 \\
\hline & Day & 144.93 & 191 & $p<0.001$ & 0.42 & 0.62 \\
\hline \multirow[t]{2}{*}{ Copepods } & Night & 54.37 & 36 & $p<0.001$ & 0.74 & 0.71 \\
\hline & Day & 36.50 & 28 & $p<0.001$ & 0.73 & 0.71 \\
\hline \multirow[t]{2}{*}{ Doliolids } & Night & 12244.11 & 275 & $p<0.001$ & 0.66 & 0.94 \\
\hline & Day & 27064.77 & 187 & $p<0.001$ & 0.55 & 0.94 \\
\hline \multirow[t]{2}{*}{ Fish larvae } & Night & 231.25 & 162 & $p<0.001$ & 0.44 & 0.77 \\
\hline & Day & 1.58 & 561 & 0.21 & 0.09 & 0.05 \\
\hline \multirow[t]{2}{*}{ Trachymedusae } & Night & 286.28 & 168 & $p<0.001$ & 0.61 & 0.78 \\
\hline & Day & 130.66 & 287 & $p<0.001$ & 0.48 & 0.55 \\
\hline \multirow[t]{2}{*}{ Diatom chains } & Night & 431.64 & 74 & $p<0.001$ & 0.72 & 0.92 \\
\hline & Day & 377.12 & 97 & $p<0.001$ & 0.75 & 0.86 \\
\hline
\end{tabular}




\begin{tabular}{lllllll} 
Acantharia radiolarians & Night & 130.32 & 176 & $\boldsymbol{p}<\mathbf{0 . 0 0 1}$ & 0.53 & 0.64 \\
& Day & 107.86 & 167 & $\boldsymbol{p}<\mathbf{0 . 0 0 1}$ & 0.47 & 0.65 \\
Radiolarian colonies & Night & 220.39 & 358 & $\boldsymbol{p}<\mathbf{0 . 0 0 1}$ & 0.61 & 0.64 \\
& Day & 116.20 & 393 & $\boldsymbol{p}<\mathbf{0 . 0 0 1}$ & 0.52 & 0.49 \\
\multirow{3}{*}{ Solitary radiolarians } & Night & 107.11 & 22.24 & $\boldsymbol{p}<\mathbf{0 . 0 0 1}$ & 0.91 & 0.89 \\
& Day & 101.06 & 14.33 & $\boldsymbol{p}<\mathbf{0 . 0 0 1}$ & 0.92 & 0.91 \\
Shrimps & Night & 685.26 & 893.08 & $\boldsymbol{p}<\mathbf{0 . 0 0 1}$ & 0.72 & 0.82 \\
& Day & 0.01 & 719.25 & 0.91 & 0.00 & 0.00 \\
\hline
\end{tabular}

373 The reference spatial distributions showed that most taxa were strongly influenced by the 374 frontal zone: fish larvae, Acantharia radiolarians and doliolids were constrained on the coastal 375 side of the front, copepods were also more concentrated towards the coast and in the upper 376 layers of the water column, while diatom chains were more abundant in the deep, offshore 377 zones (Figure 3, left column). The high spatial resolution of the data allowed us to detect smaller 378 scale patterns such as a region of slightly lower concentrations of copepods and solitary 379 radiolarians at the front (around $30 \mathrm{~m}$ depth for copepods and $50 \mathrm{~m}$ depth for radiolarians; 380 Figure 3). Solitary radiolarians also occurred in shallower water in the offshore zone compared 381 to the coastal zone (Figure 3) and precisely followed the DCM (not mapped). All these patterns, 382 from the contrasts between taxa to the fine-scale low concentration regions at the front, could 383 also be well detected on the predicted data (Figure 3, right column). The ecological 384 interpretations in terms of the distribution relative to the frontal zone would be the same. 


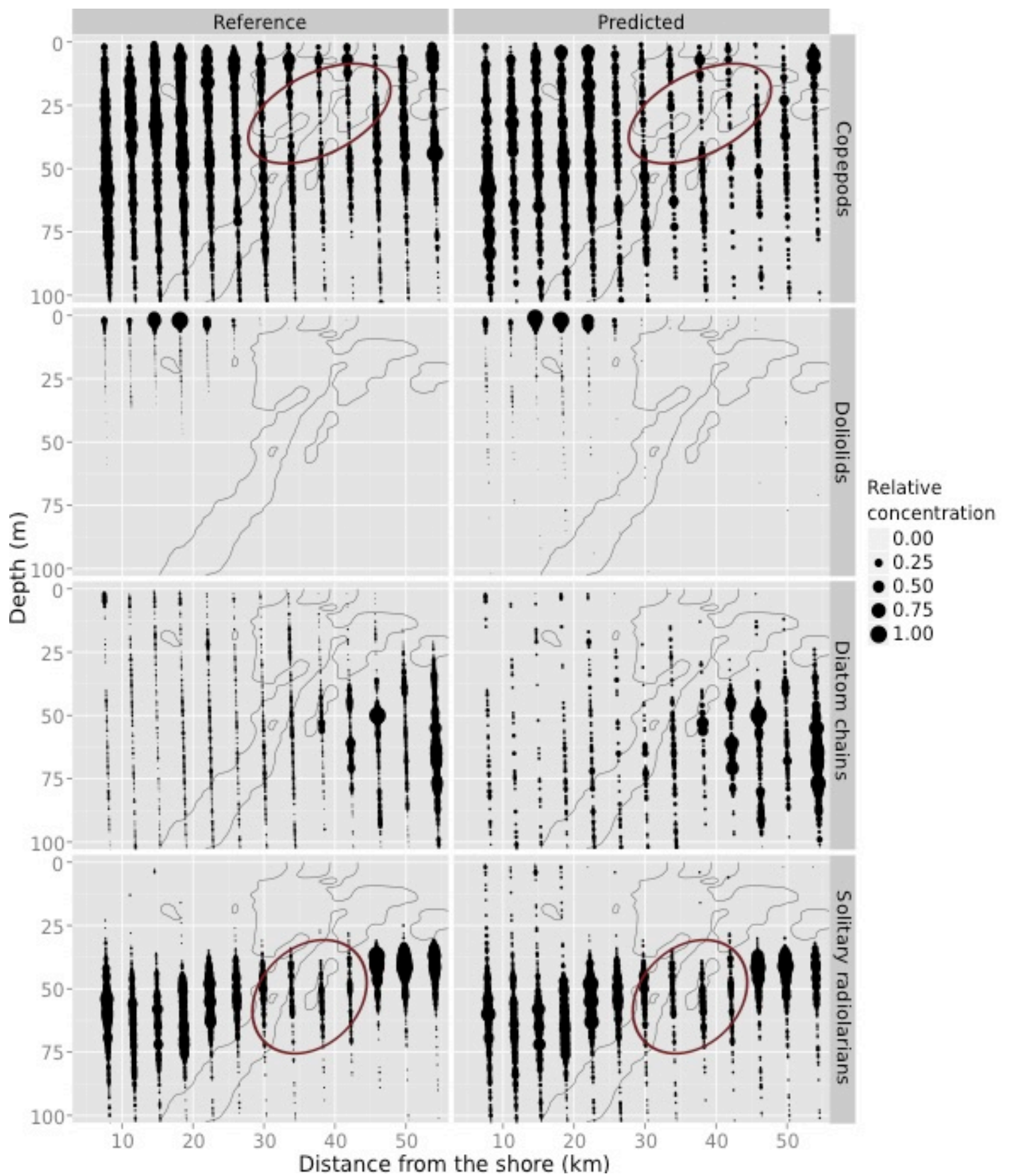

385 Figure 3. Examples of some spatial distributions in the predicted dataset (right) that are well

correlated with the reference dataset (left). From top to bottom: copepods, doliolids, diatom

chains and solitary radiolarians, all during the night transect. The $x$-axis is the distance from the coast (coastal side on the left, offshore side on the right). The area of the dots is proportional to the concentration, scaled to a maximum of 1 per taxon in each dataset, to ease comparison of patterns; the legend shows five examples but scaling is continuous. Grey lines are the 38.2 and 38.3 isohalines that delineate the frontal region. Ellipses highlight regions of lower concentration located in the frontal zone. 


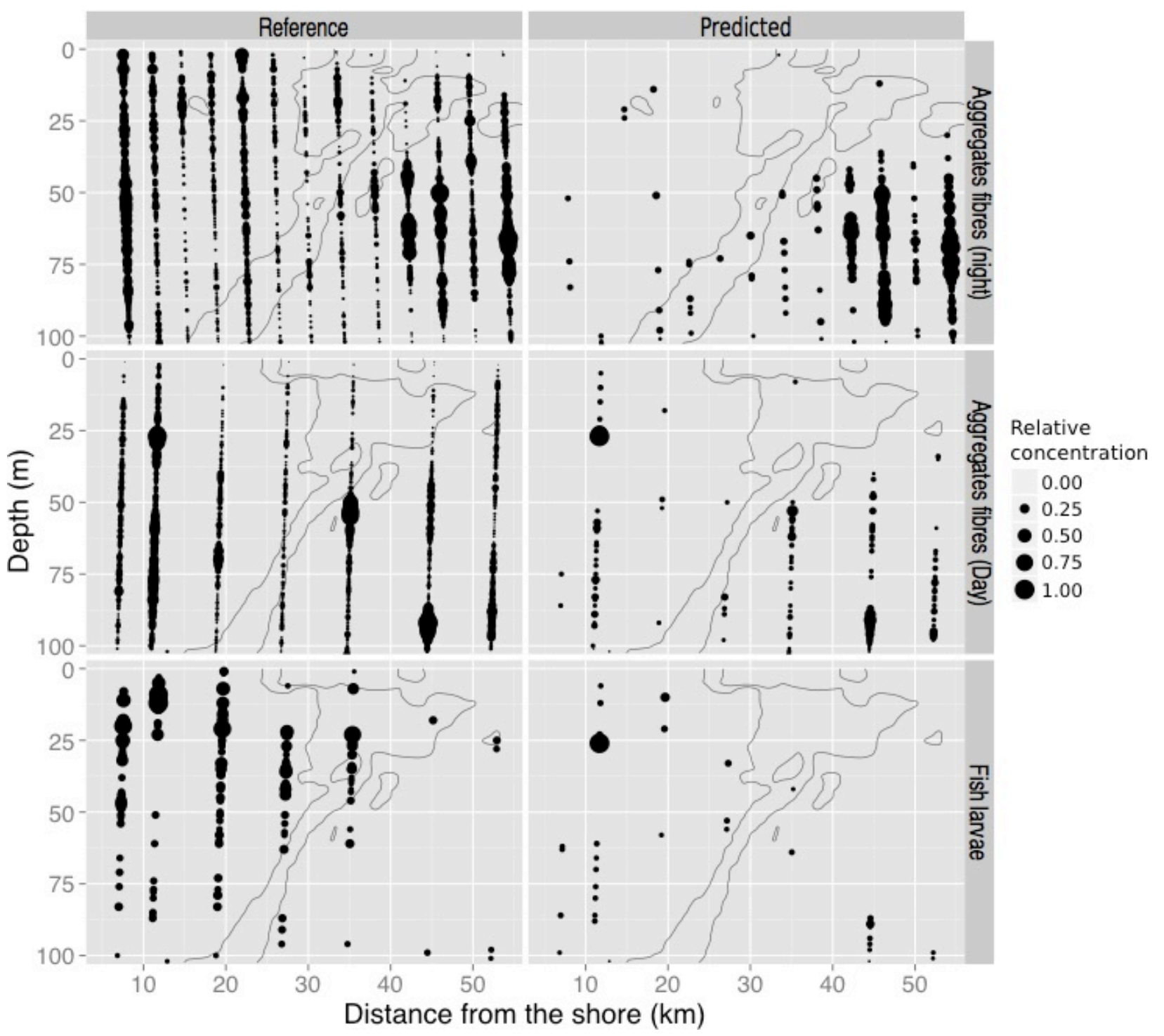

394 Figure 4. Examples of poorly predicted spatial distributions (right) compared to the reference 395 distributions (left). From top to bottom: fibres at night, then during the day and fish larvae 396 during the day. Same conventions as Figure 3.

397 The relationships between the abundance of biological taxa and various environmental 398 variables (salinity, temperature, chlorophyll a fluorescence, oxygen concentration) were very 399 similar in the reference and predicted datasets. In fact, in 69 of the 80 relationships that could 400 be modelled with GLMs, the slopes were not significantly different between the two datasets. 401 For example, copepods were more abundant in fresher waters (Figure 5), which were found on 402 the coastal side of the front. The relationships with chlorophyll $a$ fluorescence highlighted the 
404 more abundant in warmer, surface waters (Figure 5). All these conclusions would be reached 405 with the predicted dataset, which suggests that it could be used to explore and define the 406 habitat preference of various organisms.

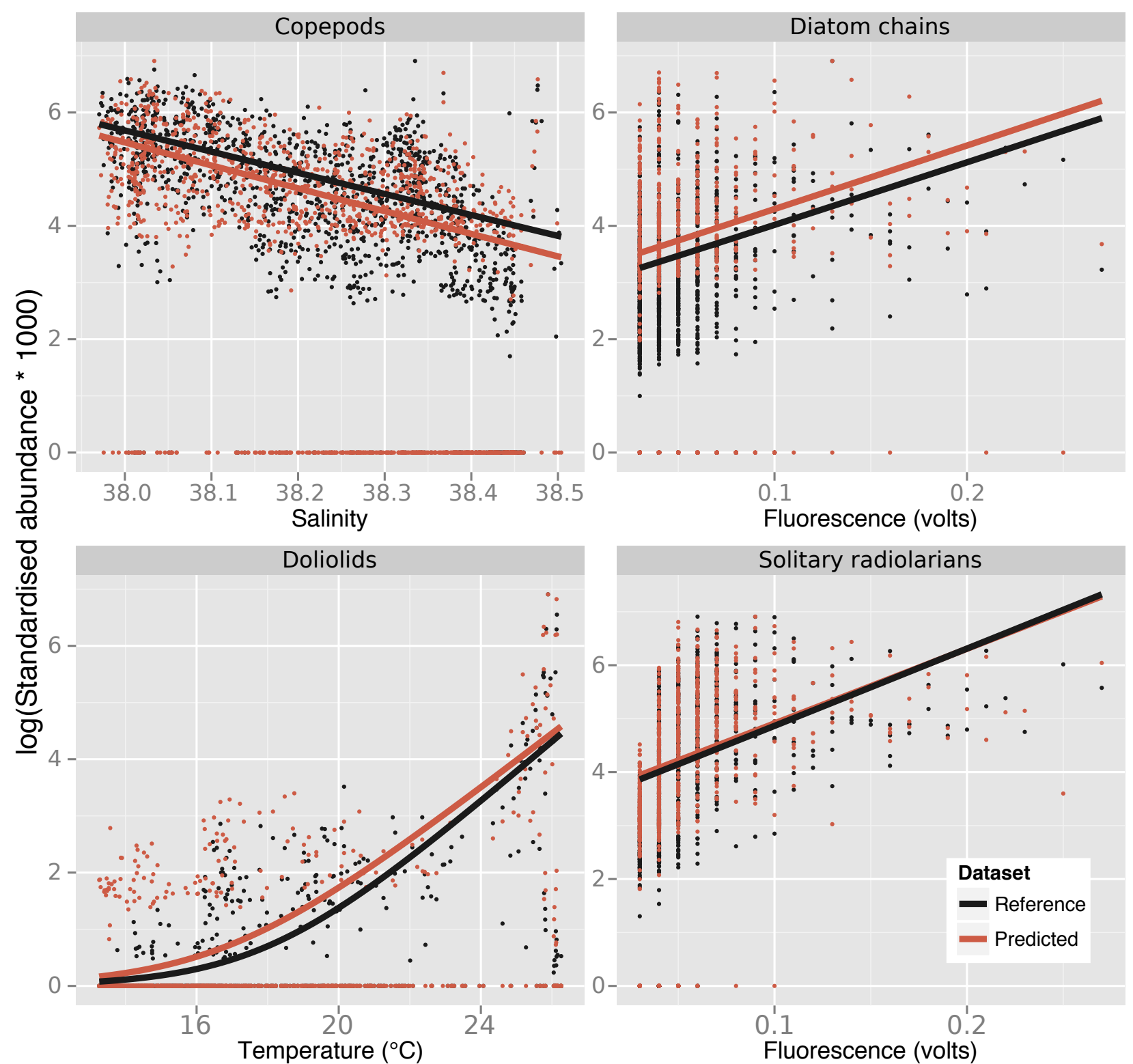

408 Figure 5. Examples of the influence of environmental variables on the distribution and concentration of several taxa for the reference dataset (black) and automatically predicted and filtered dataset (red). The lines are the fitted values of GLMs with a Poisson distribution of

411 the residuals. The slopes of the GLM based on the predicted dataset are not significantly 412 different from the ones based on the reference dataset (ANOVA, all $p>0.05$ ). Concentration is 
413 standardised between groups based on the maximum concentration per taxa and per dataset.

414 Day and night vertical distributions

415 In 8 of 12 groups, the predicted and reference vertical distributions were slightly but

416 significantly different (Solow-Kolmogorov-Smirnov test, $p<0.05$; Table 4). The four groups in

417 which the distributions were not statistically different were doliolids, Acantharia radiolarians,

418 colonial radiolarians and shrimps, although the lack of significant difference in the latter group

419 was probably due to their low overall numbers.

420 Table 4. Statistical comparisons of vertical distributions between the reference and predicted

421 datasets. The statistic and $p$-value of the Solow-Kolmogorov-Smirnov test are reported, as well

422 as the depth centre of mass of the distribution.

\begin{tabular}{|c|c|c|c|c|c|}
\hline \multirow[b]{3}{*}{ Class } & \multirow[b]{3}{*}{ Transect } & \multicolumn{4}{|c|}{ Solow K-S } \\
\hline & & \multicolumn{2}{|c|}{ Reference $\sim$ Predicted } & \multicolumn{2}{|l|}{ Depth (m) } \\
\hline & & $\mathrm{K}$ & $\mathrm{p}$ & Reference & Predicted \\
\hline \multirow[t]{2}{*}{ Dark aggregates } & Day & 3.22 & $<0.0001$ & 49.1 & 55.3 \\
\hline & Night & 3.91 & $<0.0001$ & 41.2 & 53.1 \\
\hline Light aggregates & Day & 2.98 & $<0.0001$ & 29.0 & 40.5 \\
\hline \multirow[t]{2}{*}{ Fibres } & Night & 3.97 & $<0.0001$ & 51.5 & 69.3 \\
\hline & Day & 1.61 & 0.0050 & 61.8 & 69.7 \\
\hline \multirow[t]{2}{*}{ Copepods } & Night & 2.97 & $<0.0001$ & 40.8 & 44.9 \\
\hline & Day & 1.44 & 0.0250 & 56.1 & 55.1 \\
\hline \multirow[t]{2}{*}{ Doliolids } & Night & 0.67 & 0.5690 & 5.1 & 6.9 \\
\hline & Day & 0.82 & 0.3370 & 7.1 & 8.6 \\
\hline \multirow[t]{2}{*}{ Fish larvae } & Night & 1.86 & $<0.0001$ & 16.9 & 10.9 \\
\hline & Day & 1.25 & 0.0490 & 32.6 & 52.2 \\
\hline \multirow[t]{2}{*}{ Trachymedusae } & Night & 1.44 & 0.0080 & 10.5 & 12.7 \\
\hline & Day & 1.31 & 0.0240 & 25.9 & 29.5 \\
\hline \multirow[t]{2}{*}{ Diatom chains } & Night & 3.67 & $<0.0001$ & 57.5 & 63.1 \\
\hline & Day & 1.72 & 0.0010 & 64.3 & 67.8 \\
\hline \multirow[t]{2}{*}{ Acantharia radiolarians } & Night & 1.13 & 0.1300 & 25.3 & 27.1 \\
\hline & Day & 0.69 & 0.6070 & 28.3 & 29.9 \\
\hline Radiolarian colonies & Night & 1.20 & 0.0940 & 45.4 & 44.4 \\
\hline
\end{tabular}




\begin{tabular}{llllll} 
& Day & 0.51 & 0.9020 & 45.8 & 46.3 \\
Radiolarians solitary & Night & $2.43<0.0001$ & 53.5 & 55.9 \\
& Day & $2.23<0.0001$ & 59.3 & 60.9 \\
Shrimps & Night & 1.00 & 0.1990 & 55.3 & 53.8 \\
& Day & 0.51 & 1.0000 & 49.9 & 44.1 \\
\hline
\end{tabular}

423 For many groups, except trachymedusae and fish larvae, ecological conclusions regarding depth

424 spread and preferendum would be the same in the reference and predicted dataset, even when

425 distributions were statistically different (Table 4, column "Depth (m)" and Figure 4). Similarly, an

426 analysis of diel vertical migration patterns would reach very similar conclusions on the reference

427 and on the predicted dataset. When a significant diel vertical migration was detected in the 428 reference dataset, it was also significant in the predicted one (Table 5). Conversely, radiolarian

429 colonies and Acantharia radiolarians do not appear to vertically migrate and this conclusion was 430 also reached with the predicted dataset. The range of downward migration of Trachymedusae,

431 solitary radiolarians and doliolids were also very comparable between the datasets; the same 432 was true, to a lesser extent, for calanoid copepods (Table 5, Figure 6). However, the vertical 433 migration of fish larvae was poorly predicted, with a bias towards the surface at night that was 434 much greater than in reality (Figure 6).

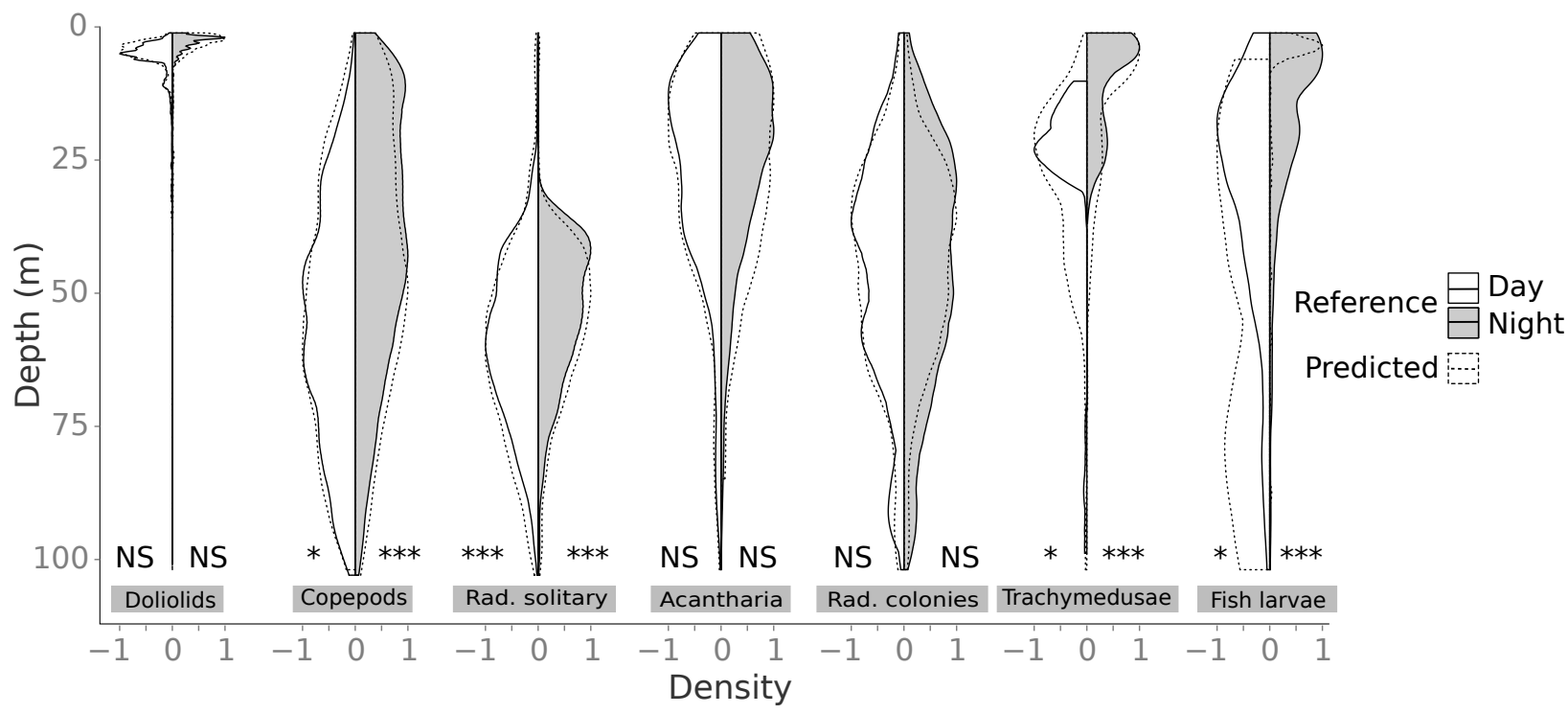

436 Figure 6. Exemples of vertical distribution during the day (left side) and at night (right side, 437 shaded) as depicted in the reference dataset (solid) and in the predicted and filtered dataset 
438 (dashed). The significant levels of the comparisons between reference and predicted 439 distributions are indicated for both day and night (NS: not significant; ${ }^{*}: p<0.05 ;{ }^{* *}: p<0.01$; $440 \quad * * *: p<0.001)$.

441 Table 5. Comparison of the resolution of diel vertical migration patterns in the reference and 442 predicted datasets. Reported for each dataset are: (i) the statistic $(K)$ of the Solow-Kolmogorov-

443 Smirnov test comparing day and night (bold when the test is significant), which quantifies the 444 overall difference in distribution, and (ii) the difference between the depth centre of mass at 445 night and during the day, a proxy for the migration range (night - day; negative means upward 446 migration at night).

\begin{tabular}{lllll}
\hline & \multicolumn{2}{l}{ Solow-K-S day night $(K)$} & \multicolumn{2}{l}{ Migration range $(\mathrm{m})$} \\
& Reference & Predicted & Reference & Predicted \\
\hline \hline Copepods & 4.10 & 2.86 & -15.3 & -10.3 \\
Doliolids & 1.16 & 1.14 & -2.1 & -1.7 \\
Fish larvae & 1.88 & 1.72 & -15.8 & -41.4 \\
Trachymedusae & 1.72 & 2.07 & -15.4 & -16.8 \\
Diatom chains & 2.53 & 2.25 & -6.8 & -4.7 \\
Acantharia radiolarians & 0.99 & 1.15 & -3.0 & -2.9 \\
Radiolarian colonies & 0.50 & 0.67 & -0.4 & -1.9 \\
Solitary radiolarians & 3.04 & 2.75 & -5.8 & -5.0 \\
Shrimps & 0.83 & 0.81 & 5.4 & 9.6 \\
\hline
\end{tabular}

\section{DISCUSSION}

448 The method presented here aimed at bypassing the manual validation of predicted 449 identifications by discarding objects classified with low confidence, hence improving precision 450 (but decreasing recall). The precision increase ( $+37 \%$ on average) was counter-balanced by a 451 recall decrease (-39\% on average), but overall classification accuracy using this method 452 increased by $16 \%$.

453 The quality and resolution of images may influence the maximum taxonomic resolution 
454 achievable by any automatic classification method. Studies based on high quality laboratory 455 imagery of plankton have usually reached higher accuracy and could resolve a larger number of 456 groups (e.g. 22 phytoplankton groups in Sosik and Olson (2007); 25 zooplankton groups in 457 Fernandes et al. (2009); 10-20 groups in Benfield et al., 2007) than studies based on images of 458 zooplankton captured in situ which are usually of lesser quality (e.g. three groups with SVM, 459 achieving 80\% accuracy (Bi et al., 2015); seven groups with random subspace model achieving $460>90 \%$ precision but in a self-prediction of the learning set (Zhao et al., 2010); five to seven 461 groups with neural networks, reaching 60 to $80 \%$ accuracy; Davis et al., 2004; Hu and Davis, 462 2005). While only a formal comparison, using the same dataset (e.g. Fei-Fei et al. 2007), could 463 resolve the differences between classification methods, comparing the size orders of 464 classification metrics between studies can still be informative. Here, our classifier dealt with 14 465 groups and, after filtering, reached $56.3 \%$ general accuracy as well as $84 \%$ precision on 466 biological groups. This falls within the higher range in terms of precision and number of 467 predicted groups compared to previous studies on in situ images of zooplankton, especially 468 considering that $67-83 \%$ accuracy is often used as a benchmark for plankton classifications 469 (Culverhouse et al., 2003; Hu and Davis, 2005). While there is still room for improvement in the 470 original classification rates, the data filtering method presented in this study markedly improved 471 the performance of the standard ZooProcess/PkID classification.

472 Large image datasets are likely to become increasingly common thanks to the development of 473 affordable high-frequency, high-resolution cameras like the one installed on ISIIS. In such big 474 datasets, all the information may not be essential and some may be efficiently omitted (Bi et al., 475 2015). The filtering approach used in this study considerably subsampled the data (72\% of 476 objects were discarded) in order to focus only on well-predicted objects. Despite this high 477 subsampling rate, the two dimensional, and to a lesser extent vertical, distributions of many 478 classes were not significantly different between the subsampled and the total, reference 479 dataset. In addition, the poorly predicted groups could be easily identified by the sparseness of 480 their predicted distribution and/or the high proportion of discarded images (>90\%). This 481 provided an additional control for the validation of automatically predicted distributions. 
482 More importantly, studying realistic ecological questions with the reference and predicted 483 datasets resulted in the same conclusions.

484 The size distribution of objects of most classes (9 of 12) were similarly represented in both the 485 automatically predicted and filtered dataset (Figure 2). In the three other classes, the filtering 486 method discarded small objects $(<5 \mathrm{~mm})$ more often than larger ones, possibly because small 487 objects are more prone to be misclassified due to their lower level of detail.

488 The results also highlighted the foremost influence of the frontal structure, marked by a salinity 489 gradient, on the distributions of organisms along the across-front section (Figure 5). This is 490 consistent with many studies from the literature (Boucher, 1984; Goffart et al., 1995; Pedrotti 491 and Fenaux, 1992). For example, some taxa like Acantharia radiolarians, doliolids, fish larvae, 492 and, to a lesser extent, copepods were mostly observed in the coastal or frontal zones and in 493 the upper $50 \mathrm{~m}$ of the water column (Figures 3 and 4). Both datasets allowed us to relate the 494 abundance of various taxa to the salinity gradient, which marks the frontal region, the intensity 495 of the fluorescence of chlorophyll $a$ associated with the DCM, or the warmer temperatures 496 found near the surface (Figure 5). Overall, $86 \%$ of the relationships with environmental variables 497 that were explored were not statistically different between the two datasets. Finally, diatom 498 chains were most abundant in the deeper layers of the central zone, where copepod 499 concentrations were the lowest (Figure 3), suggesting a possible influence of grazing. These 500 results suggest that species-environment relationships or interspecific interactions can be 501 studied at the very fine scales that imaging techniques provide without requiring labour502 intensive validation.

503 Changes in vertical distributions between day and night, even over less than $10 \mathrm{~m}$, could also be 504 detected in the predicted data for most taxa, with a power and resolution similar to that of the 505 reference dataset (Figure 6; Table 4). Diel vertical migrations of copepods and medusae are well 506 described in the literature (e.g. Hays, 2003; Sabatés et al., 2010). However, the apparent $<10 \mathrm{~m}$ 507 vertical movements of solitary Colodaria radiolarians or the $2 \mathrm{~m}$ downward displacement of 508 doliolids during the day are not documented in prior studies, possibly because they were missed 509 by other sampling methods with lower vertical resolutions. The ecological significance of these 
510 fine scale vertical movements is not within the scope of this study, but the fact that they could

511 be detected highlights the efficacy of both high frequency imaging systems and this automatic

512 classification and filtration method in exploring microscale processes in the plankton.

513 Nonetheless, some taxa share striking similarities and only a trained expert may be able to

514 differentiate between them. These size and shape resemblances can lead to high error rates in

515 the automatic prediction of these groups (Fernandes et al., 2009). Automatic classification

516 methods may never reach the taxonomical resolution achieved by experts observing plankton

517 through a stereomicroscope (even if both make mistakes; Culverhouse et al., 2003). Still,

518 combined with data filtering, automatic classification can accurately describe spatial

519 distributions when low taxonomical resolution is acceptable, for example to study broad groups

520 that provide an environmental or biological context for a species of interest. Eventually, manual

521 validation is likely to still be required in order to focus on some specific taxonomic group. For

522 example, fish larvae imaged here were very diverse and appeared similar to appendicularians

523 and chaetognaths in terms of body size, shape and opacity. As a result, this group was badly

524 predicted and manual methods would still be necessary to tease apart their distribution.

525 Using the proposed method, the processing of 1.5 million objects required only the manual 526 classification of 5979 objects $(0.41 \%)$. It could properly describe distribution patterns, but the 527 drastic filtering process would lead to vastly underestimating the abundances of all groups. In 528 future studies, these underestimated abundances could be scaled up by quantifying, in each 529 class, the proportion of discarded and wrongly classified objects (e.g. with a confusion matrix). 530 This quantification requires to manually validate a random subset of images of each category of 531 the predicted dataset, thus requiring additional human effort. However, during validation of the 5321.5 million in this project, the throughput of a trained operator was about 10,000 objects per 533 day. Therefore, human effort on the order of a couple of weeks would probably yield enough 534 data to correct abundances and further control the error rate for the rest of the predicted 535 images.

536 The present method is based on two features shared by all machine learning methods: the use 537 of a learning set to teach the model how to differentiate between classes and the computation 
538 of a final score, or probability, for each object to belong in each class. The probability thresholds

539 for the filtering step are computed by cross-validating the learning set and do not require 540 additional manual sorting. In many cases, Random Forest, working on a few dozen features

541 deterministically measured on the object, came out as the most efficient classifier for plankton

542 data (e.g. Bell and Hopcroft, 2008; Fernandes et al., 2009; Gorsky et al., 2010). Yet, overall

543 accuracy was never more than $80 \%$. However, deep machine learning methods such as

544 convolutional neural networks (CNNs) are emerging as promising tools for a range of image

545 classification tasks (Krizhevsky et al., 2012; Simonyan and Zisserman, 2015). Applying the

546 filtering method described here to classifiers that already achieve high accuracy on large

547 datasets may eventually lead to near-perfect automatic classifications, without discarding too

548 much information. Such a combination would allow the handling of large plankton imaging 549 datasets that are still challenging to process rapidly and accurately (Benfield et al., 2007;

550 Culverhouse et al., 2006), hence providing appropriate tools to explore the finescale and 551 microscale processes occurring in the oceans.

\section{ACKNOWLEDMENTS}

553 The authors thank A. Maupetit and F. Ferrando for their help with the manual identification, the

554 crew of the R/V Tethys 2 operating during the VISUFRONT cruise and CNRS/INSU for the ship 555 time. This work was supported by a grant from the Partner University Fund to JOI and RKC. RF's

556 doctoral fellowship was provided by the French Ministry for Education and Research $\left(\mathrm{n}^{\circ}\right.$ 557 247/2012).

558 REFERENCES

559 Bakun, A., 2006. Fronts and eddies as key structures in the habitat of marine fish larvae: 560 opportunity, adaptive response. Sci. Mar. 105-122. 
Belkin, I.M., 2002. Front. Interdiscip. Encycl. Mar. Sci.

562 Belkin, I.M., Cornillon, P.C., Sherman, K., 2009. Fronts in Large Marine Ecosystems. Prog. 563 Oceanogr. 81, 223-236.

564 Bell, J.L., Hopcroft, R.R., 2008. Assessment of Zoolmage as a tool for the classification of 565 zooplankton. J. Plankton Res. 30, 1351-1367.

566 Benfield, M., Grosjean, P., Culverhouse, P., Irigolen, X., Sieracki, M., Lopez-Urrutia, A., Dam, H., 567 Hu, Q., Davis, C., Hanson, A., Pilskaln, C., Riseman, E., Schulz, H., Utgoff, P., Gorsky, G., 568 2007. RAPID: Research on Automated Plankton Identification. Oceanography 20, 172-187.

569 Benfield, M.C., Davis, C.S., Wiebe, P.H., Gallager, S.M., Gregory Loughj, R., Copley, N.J., 1996.

570 Video Plankton Recorder estimates of copepod, pteropod and larvacean distributions from 571 a stratified region of Georges Bank with comparative measurements from a MOCNESS 572 sampler. Deep. Res. Part II Top. Stud. Oceanogr. 43, 1925-1945.

573 Benoit-Bird, K.J., McManus, M.A., 2012. Bottom-up regulation of a pelagic community through 574 spatial aggregations. Biol. Lett. 8, 813-816.

575 Bi, H., Cook, S., Yu, H., Benfield, M.C., Houde, E.D., 2013. Deployment of an imaging system to 576 investigate fine-scale spatial distribution of early life stages of the ctenophore Mnemiopsis leidyi in Chesapeake Bay. J. Plankton Res. 35, 270-280.

Bi, H., Guo, Z., Benfield, M.C., Fan, C., Ford, M., Shahrestani, S., Sieracki, J.M., 2015. A SemiAutomated Image Analysis Procedure for In Situ Plankton Imaging Systems. PLoS One 10, e0127121.

Boucher, J., 1984. Localization of zooplankton populations in the Ligurian marine front: role of ontogenic migration. Deep Sea Res. 31, 469-484. zooplankton populations in relation to the physical structure in the Ligurian Sea Front. J. Mar. Res. 45, 133-173. 
Breiman, L., 2001. Random Forests. Mach. Learn. 45, 5-32.

587 Cowen, R.K., Greer, A.T., Guigand, C.M., Hare, J.A., Richardson, D.E., Walsh, H.J., 2013. 588 Evaluation of the In Situ Ichthyoplankton Imaging System (ISIIS): comparison with the 589 traditional (bongo net) sampler. Fish. Bull. 111, 1-12.

590

Cowen, R.K., Guigand, C.M., 2008. In situ ichthyoplankton imaging system (ISIIS): system design 591 and preliminary results. Limnol. Oceanogr. Methods 6, 126-132.

592

Culverhouse, P.F., Williams, R., Benfield, M., Flood, P.R., Sell, A.F., Mazzocchi, M.G., Buttino, I., 593 Sieracki, M., 2006. Automatic image analysis of plankton: Future perspectives. Mar. Ecol. Prog. Ser. 312, 297-309.

595

Culverhouse, P.F., Williams, R., Reguera, B., Herry, V., González-Gil, S., 2003. Do experts make 596 mistakes? A comparison of human and machine identification of dinoflagellates. Mar. Ecol. Prog. Ser. 247, 17-25.

Davis, C.S., Gallager, S.M., Solow, A.R., 1992. Microaggregations of oceanic plankton observed 599 by towed video microscopy. Science. 257, 230-232.

600

Davis, C.S., Hu, Q., Gallager, S.M., Tang, X., Ashjian, C.J., 2004. Real-time observation of taxa601 602 specific plankton distributions: An optical sampling method. Mar. Ecol. Prog. Ser. 284, 7796.

Dutilleul, P., Clifford, P., Richardson, S., Hemon, D., 1993. Modifying the t Test for Assessing the 604 Correlation Between Two Spatial Processes. Biometrics 49, 305.

605 Espinasse, B., Zhou, M., Zhu, Y., Hazen, E.L., Friedlaender, A.S., Nowacek, D.P., Chu, D., Carlotti, 606 F., 2012. Austral fall-winter transition of mesozooplankton assemblages and krill 607 $608 \quad 63-80$. aggregations in an embayment west of the Antarctic Peninsula. Mar. Ecol. Prog. Ser. 452,

Fei-Fei, L., Fergus, R., Perona, P., 2007. Learning generative visual models from few training 610 examples: An incremental bayesian approach tested on 101 object categories. Comput. Vis. 
612 Fernandes, J.A., Irigoien, X., Boyra, G., Lozano, J.A., Inza, I., 2009. Optimizing the number of 613 classes in automated zooplankton classification. J. Plankton Res. 31, 19-29.

614 Gasparini, S., Antajan, E., 2013. PLANKTON IDENTIFIER: a software for automatic recognition of 615 planktonic organisms.

616 Goffart, A., Hecq, J.-H., Prieur, L., 1995. Controle du phytoplancton du bassin Ligure par le front 617 liguro-provencal (secteur Corse). Oceanol. Acta 18, 329-342.

618 Gorsky, G., Ohman, M.D., Picheral, M., Gasparini, S., Stemmann, L., Romagnan, J.B., Cawood, A., 619 Pesant, S., García-Comas, C., Prejger, F., 2010. Digital zooplankton image analysis using the 620 ZooScan integrated system. J. Plankton Res. 32, 285-303.

621 Greer, A.T., Cowen, R.K., Guigand, C.M., Hare, J.A., 2015. Fine-scale planktonic habitat 622 623 partitioning at a shelf-slope front revealed by a high-resolution imaging system. J. Mar. Syst. 142, 111-125.

624 Greer, A.T., Cowen, R.K., Guigand, C.M., Hare, J.A., Tang, D., 2014. The role of internal waves in 625 larval fish interactions with potential predators and prey. Prog. Oceanogr. 127, 47-61.

626 Greer, A.T., Cowen, R.K., Guigand, C.M., McManus, M.A., Sevadjian, J.C., Timmerman, A.H. V., 627 2013. Relationships between phytoplankton thin layers and the fine-scale vertical 628 distributions of two trophic levels of zooplankton. J. Plankton Res. 35, 939-956.

629 Grimes, C.B., Finucane, J.H., 1991. Spatial distribution and abundance of larval and juvenile fish, 630 chlorophyll and macrozooplankton around the Mississippi River discharge plume, and the 631 role of the plume in fish recruitment. Mar. Ecol. Prog. Ser. 75, 109-119.

632 Hays, G.C., 2003. A review of the adaptive significance and ecosystem consequences of 633 zooplankton diel vertical migrations. Hydrobiologia 503, 163-170.

634 Herman, A.W., Mitchell, M.R., Young, S.W., 1984. A continuous pump sampler for profiling 
$636 \mathrm{Hu}, \mathrm{Q} .$, Davis, C., 2005. Automatic plankton image recognition with co-occurrence matrices and 637 Support Vector Machine. Mar. Ecol. Prog. Ser. 295, 21-31.

638 Irisson, J.-O., Paris, C.B., Guigand, C., Planes, S., 2010. Vertical distribution and ontogenetic 639 "migration" in coral reef fish larvae. Limnol. Oceanogr. 55, 909-919.

640 Krizhevsky, A., Sutskever, I., Hinton, G.E., 2012. ImageNet Classification with Deep Convolutional $641 \quad$ Neural Networks. Adv. Neural Inf. Process. Syst. 1-9.

642 Legendre, L., Le Fèvre, J., 1991. From Individual Plankton Cells To Pelagic Marine Ecosystems 643 And To Global Biogeochemical Cycles, in: Demers, S. (Ed.), Particle Analysis in 644 Oceanography SE - 11, NATO ASI Series. Springer Berlin Heidelberg, pp. 261-300.

645 Li, Z., Member, S., Zhao, F., Liu, J., Member, S., Qiao, Y., 2014. Pairwise Nonparametric 646 Discriminant Analysis for Binary Plankton Image Recognition. IEEE J. Ocean. Eng. 39, 695$647 \quad 701$.

648 Lough, R.G., Broughton, E.A., 2007. Development of micro-scale frequency distributions of 649 plankton for inclusion in foraging models of larval fish, results from a Video Plankton 650 Recorder. J. Plankton Res. 29, 7-17.

651 Luo, J., Grassian, B., Tang, D., Irisson, J., Greer, A., Guigand, C., McClatchie, S., Cowen, R., 2014. 652 Environmental drivers of the fine-scale distribution of a gelatinous zooplankton community 653 across a mesoscale front. Mar. Ecol. Prog. Ser. 510, 129-149.

MacLeod, N., Benfield, M., Culverhouse, P., 2010. Time to automate identification. Nature 467, 655 154-155.

656 McClatchie, S., Cowen, R., Nieto, K., Greer, A., Luo, J.Y., Guigand, C., Demer, D., Griffith, D., 657 Rudnick, D., 2012. Resolution of fine biological structure including small narcomedusae 658 across a front in the Southern California Bight. J. Geophys. Res. 117, C04020. 
659 660

661 662

Neilson, J.D., Perry, R.I., 1990. Diel vertical migrations of marine fishes: an obligate or facultative process? Adv. Mar. Biol. 26, 115-168.

Olson, D.B., Hitchcock, G.L., Mariano, A.J., Ashjian, C.J., Peng, G., Nero, R.W., Podesta, G.P., 1994. Life on the edge: marine life and fronts. Oceanography 7, 52-60.

Pedrotti, M.L., Fenaux, L., 1992. Dispersal of echinoderm larvae in a geographical area marked by upwelling (Ligurian Sea, NW Mediterranean). Mar. Ecol. Prog. Ser. 86, 217-227.

Picheral, M., Guidi, L., Stemmann, L., Karl, D., Iddaoud, G., Gorsky, G., 2010. The Underwater Vision Profiler 5: An advanced instrument for high spatial resolution studies of particle size spectra and zooplankton. Limnol. Oceanogr. Methods 8, 462-473.

Pinel-Alloul, B., 1995. Spatial heterogeneity as a multiscale characteristic of zooplankton community, in: Space Partition within Aquatic Ecosystems. Springer, pp. 17-42.

Sabatés, A., Pagès, F., Atienza, D., Fuentes, V., Purcell, J.E., Gili, J.M., 2010. Planktonic cnidarian distribution and feeding of Pelagia noctiluca in the NW Mediterranean Sea. Hydrobiologia 645, 153-165.

Sammari, C., Millot, C., Prieur, L., 1995. Aspects of the seasonal and mesoscale variabilities of the Northern Current in the western Mediterranean Sea inferred from the PROLIG-2 and PROS-6 experiments. Deep Sea Res. Part I Oceanogr. Res. Pap. 42, 893-917.

Samson, S., Hopkins, T., Remsen, A., Langebrake, L., Sutton, T., Patten, J., 2001. A system for high-resolution zooplankton imaging. IEEE J. Ocean. Eng. 26, 671-676.

Simonyan, K., Zisserman, A., 2015. Very Deep Convolutional Networks for Large-Scale Image Recoginition. Intl. Conf. Learn. Represent. 1-14.

Smeti, H., Pagano, M., Menkes, C., Lebourges-Dhaussy, A., Hunt, B.P., Allain, V., Rodier, M., de Boissieu, F., Kestenare, E., Sammari, C., 2015. Spatial and temporal variability of zooplankton off New Caledonia (Southwestern Pacific) from acoustics and net measurements. J. Geophys. Res. Ocean. 120, 1-25. 
684 Solow, A.R., Bollens, S.M., Beet, A., 2000. Comparing two vertical plankton distributions. Limnol. 685 Oceanogr. 45, 506-509.

686 Sosik, H.M., Olson, R.J., 2007. Automated taxonomic classification of phytoplankton sampled 687 with imaging in-flow cytometry. Limnol. Oceanogr. Methods 5, 204-216.

688 Vandromme, P., Stemmann, L., Berline, L., Gasparini, S., Mousseau, L., Prejger, F., Passafiume, 689 O., Guarini, J.-M., Gorsky, G., 2011. Inter-annual fluctuations of zooplankton communities 690 in the Bay of Villefranche-sur-mer from 1995 to 2005 (Northern Ligurian Sea, France). $691 \quad$ Biogeosciences 8, 3143-3158.

692 Wiebe, P.H., Benfield, M.C., 2003. From the Hensen net toward four-dimensional biological 693 oceanography. Prog. Oceanogr. 56, 7-136.

694 Ye, L., Chang, C.Y., Hsieh, C.H., 2011. Bayesian model for semi-automated zooplankton 695 classification with predictive confidence and rapid category aggregation. Mar. Ecol. Prog. 696 Ser. 441, 185-196.

697 Zhao, F., Lin, F., Seah, H.S., 2010. Binary SIPPER plankton image classification using random 698 subspace. Neurocomputing 73, 1853-1860. 